\title{
Individual social capital, neighbourhood deprivation, and self- rated health in England
}

\author{
Accepted for publication in Social Science \& Medicine
}

\section{Authors:}

Verhaeghe Pieter-Paul, Health and Demographic Research Centre, University of Ghent, Belgium Tampubolon Gindo, Institute for Social Change, University of Manchester, UK

\section{Corresponding author:}

Verhaeghe Pieter-Paul, pieterpaul.verhaeghe@ugent.be

\section{Acknowledgements:}

This research has been financed by the Research Foundation - Flanders (FWO). We would like to thank the original creators of Taking Part and the UK Data Archive for making Taking Part available for free. However, the original data creators, depositors or copyright holders and the UK Data Archive bear no responsibility for our further analyses or interpretations. In addition, we would like to thank Elise Pattyn, Adi Pierewan, Lore Van Praag, Paul Widdop and the anonymous reviewers for their help with writing this manuscript.

\section{Key words:}

deprivation; England; neighbourhoods; position generator; self-rated health; social capital; social networks 


\begin{abstract}
Individual social capital is increasingly considered to be an important determinant of an individual's health. This study examines the extent to which individual social capital is associated with self-rated health and the extent to which individual social capital mediates the relationship between neighbourhood deprivation and self-rated health in an English sample. Individual social capital was conceptualized and operationalized in both the social cohesion- and network resource tradition, using measures of generalized trust, social participation and social network resources. Network resources were measured with the position generator. Multilevel analyses were applied to wave 2 and 3 of the Taking Part Surveys of England, which consist of face-to-face interviews among the adult population in England ( $\mathrm{N}_{\mathrm{i}}=25,366$ respondents, $\mathrm{N}_{\mathrm{j}}=12,388$ neighbourhoods). The results indicate that generalized trust, participation with friends and relatives and having network members from the salariat class are positively associated with self-rated health. Having network members from the working class is, however, negatively related to self-rated health. Moreover, these social capital elements are partly mediating the negative relationship between neighbourhood deprivation and self-rated health.
\end{abstract}




\section{Individual social capital, neighbourhood deprivation, and self-}

\section{rated health in England}

\section{Introduction}

In the past two decades, social capital has increasingly gained attention in health research (Kawachi et al., 2008). Social capital can be conceptualized at both the collective and individual level (Ferlander, 2007; Kawachi et al., 2008). Collective social capital refers to characteristics of communities, workplaces, or neighbourhoods, whereas individual social capital concerns cognitive and structural elements related to social relationships of individuals. This study examines the association between individual social capital and self-rated health and investigates the extent to which individual social capital mediates the relationship between neighbourhood deprivation and self-rated health.

The increased interest in social capital has seen the development of numerous conceptualizations and operationalizations of social capital. Most health studies rely upon Fukuyama's (1995) and Putnam's (2000) conceptualizations of social capital, which focus on elements such as interpersonal trust, norms of reciprocity and mutual aid, and social involvement. These elements foster social cohesion and cooperation with several beneficial outcomes. Research has found that beneficial health outcomes are associated with having trust in others (Fujiwara \& Kawachi, 2008; Giordano \& Lindström, 2010; Hyyppä et al., 2007; Nieminen et al., 2010; Poortinga, 2006; Snelgrove et al., 2009; Tampubolon et al., 2011), socializing with friends, relatives, colleagues or neighbours (Veenstra, 2000; Ziersch, 2005), and participating in associations (Giordano \& Lindström, 2010; Giordano et al., 2011; Hyyppä et al., 2007; Lindström et al., 2004; Nieminen et al., 2010; Poortinga, 2006). However, the evidence for the health benefits of norms of reciprocity and mutual aid is inconclusive (Fujiwara \& Kawachi, 2008; Giordano et al., 2011). This school of social capital is labelled as the 'social cohesion' approach (Ferlander, 2007). 
In contrast, other scholars have stressed that resources embedded in social networks are a crucial element of social capital. This school of social capital is rooted in the work of Bourdieu (1986) and Lin (2001) and is called the 'network resources' approach (Ferlander, 2007). Although health studies using this approach are less numerous, they have shown that network resources are positively associated with self-rated health (Carpiano \& Hystad, 2011; Moore et al., 2011; Song \& Lin, 2009; Verhaeghe et al., 2012) and several mental health outcomes (Acock \& Hurlbert, 1993; Haines et al., 2011; Song, 2011; Song \& Lin, 2009; Webber \& Huxley, 2007;).

Moreover, because the resources approach pays more attention to issues of deprivation and inequality, it has shown that having network resources could be related to having poorer health too. Moore (2009) found, for example, that having socio-economically strong and diverse network members is associated with a lower sense of mastery among the lower-educated. Moreover, Verhaeghe and colleagues (2012) found that knowing working class people is associated with worse self-rated health. These findings corroborate with the idea of Portes (1998), that social capital has a 'downside' for society too.

Network members' resources could affect health both positively and negatively through several pathways (Kawachi \& Berkman, 2001; Song, 2011). Firstly, neo-materialist explanations emphasize the (lack of) access to health-related resources through network members (such as money for healthy food, access to health care or health insurance) or the exposure to socio-economic stressors (such as job loss or mortgage delinquencies of network members). Secondly, network members' resources could affect health through psychosocial mechanisms. Carpiano and Hystad (2011), for example, found that network resources are positively associated with a sense of belonging. Moreover, Song (2011) found that the subjective social status is partly mediating the negative association between network resources and psychological distress. Finally, from a health lifestyle perspective (Abel \& Frohlich, 2012; Cockerham, 2005), we could argue that because people are embedded and socialized in networks, network members' resources either empower or constrain people's choice of healthrelated behavioural options (e.g. physical activity, diet, alcohol and tobacco consumption). Many 
studies have documented the structuring impact of network members' resources on health norms, needs and eventually practices (Smith \& Christakis, 2008).

While there is a growing agreement that both approaches capture valid elements of the concept of social capital (Ferlander, 2007, Kawachi et al., 2008), studies examining the impact of social capital on health using both approaches are very scarce. Noteworthy exceptions are the studies of Moore and colleagues among the adult population of Montreal in Canada (Moore et al., 2009; Moore et al., 2011). Moore and colleagues found independent positive associations between trust, social participation, and network resources and self-rated health, but only an independent negative association of network resources with overweight and obesity. Since both approaches highlight distinct elements of social capital and distinct mechanisms linking social capital to health, a comprehensive national study examining the influence of social capital on health from both perspectives is needed. Such a study would shed light on the relative importance of both approaches in explaining health.

Therefore, the first research question concerns the relative contribution of each perspective on individual social capital to health. We hypothesize that trust, social participation and socioeconomically strong network resources are positively related to health, whereas socio-economically weak network resources are negatively related to health.

Research has shown that disadvantaged communities are often characterized by low levels of trust, participation, and socio-economically strong network resources (Cattell, 2001; McCulloch, 2003; Wilson, 1987). Moreover, studies have found that the bad reputation of deprived areas limit their inhabitants' ability to make (resourceful) connections outside the neighbourhood too (Cattell, 2001; Stephens, 2008).

At the same time, socio-economic neighbourhood conditions matter for health, over and above one's own socio-economic position (Diex-Roux, 2001; Weden et al., 2008). Most studies have considered collective efficacy and neighbourhood disorder (Aneshensel \& Sucoff, 1996; Ross \& Mirowsky, 2001; 
Weden et al., 2008), social stress (Pattyn et al., 2011), and collective social capital (Carpiano, 2007; Drukker et al., 2003; Mohan et al., 2005; Stafford et al., 2008) to explain this link between neighbourhood disadvantage and health. However, very few studies have examined the role of individual social capital, among other mechanisms, in mediating the relationship between neighbourhood disadvantage and health (Carpiano, 2006; Cattell, 2001).

The exception is a study by Haines and colleagues (2011). They found that network resources mediate the contextual effect of neighbourhood disadvantage on depressive symptoms. Their study has, however, a few limitations. Firstly, Haines (2011) examined the mediating role of individual social capital in a mid-sized southern city in the United States. Their sample was small and more than half of respondents lived in disadvantaged neighbourhoods. Because virtually all African Americans in their sample lived in disadvantaged neighbourhoods and virtually all non-African Americans lived in advantaged areas, the effects of socio-economic disadvantage could not be separated from effects of ethnic composition. Secondly, the authors did not examine the mediating effects of trust and social participation. They considered social capital only from the resource approach and ignored the social cohesion approach. Since Putnam's social capital elements have been linked to both neighbourhood disadvantage and health, the mediation effect could have been underestimated.

Therefore, the second research question posed here concerns the extent to which the negative relationship between neighbourhood deprivation and health is mediated by network resources, trust, and social participation. We hypothesize that these elements could, to some extent, mediate this negative relationship.

We aim to contribute to the literature by examining the direct and mediating effects of individual social capital, using measures representing both approaches to the concept of social capital. Moreover, our multi-level analyses are based on a large-scale, representative sample of England's adult population and neighbourhoods. Previous studies in England have examined associations of trust and social participation with health (Giordano \& Lindström, 2010; Giordano et al., 2011; Mohan et al., 
2005; Poortinga, 2006), or have examined associations of network resources with health (Webber \& Huxley, 2007), but these associations have never been investigated simultaneously.

Finally, our study differs from the work of Haines et al. (2011) in that we analyse self-rated health as the health outcome. We focus on self-rated health for two reasons. Firstly, self-rated health is a strong predictor of mortality (Idler \& Benyamini, 1997) and is highly correlated with objective health measurements (Simon et al., 2005). Secondly, Ziersch (2005) suggests that social ties are especially important for mental health and Haines (2011) also recommends examining less evident outcomes, such as self-rated health.

\section{Methods}

Data

We used data from wave 2 and 3 of the Taking Part Surveys of England, which consist of 49,894 faceto-face interviews concerning participation in various leisure activities among the adult population in England (Aust \& Vine, 2007). Wave 2 was collected between July 2006 and June 2007, and wave 3 between July 2007 and June 2008. Response rates were 55\% and 59\%. Data are representative for the non-institutionalized adult population in England. Questions on trust and participation are only asked to a randomly taken sample of respondents. This sample consists of 25,366 respondents.

\section{Individual characteristics}

To assess self-rated health, respondents were asked to rate their health in general. Answer categories ranged from 'very poor', 'poor', 'fair', 'good', and 'very good'. In this paper, we dichotomized selfrated health in two categories: poor health (answers 'very poor', 'poor', and 'fair') and good health (answers 'good' and 'very good'). 
Three elements of social capital were measured: generalized trust, social participation, and network resources. Generalized trust was assessed with the question: "Generally speaking, would you say that most people (1) can be trusted or (2) you cannot be too careful in dealing with people?" Some respondents $(8.5 \%)$ answered spontaneously that 'it depends'. We dichotomized this variable into a 'distrust' category, including the answers 'you can't be too careful' and 'it depends', and a 'trust'category.

Social participation was measured by asking how often respondents meet up with friends (1), and with relatives outside the household (2). Response categories were 'never', 'less often than once a month', 'once or twice a month', 'once or twice a week', and 'most days'. These two variables were dichotomized because exploratory analyses showed that their associations with self-rated health are non-linear. ${ }^{2}$ Participation with friends was dichotomised into low participation (less often than once a month) and high participation (once or twice a month or more). Participation with relatives was dichotomized into low participation (never) and high participation (less often than once a month or more).

Social network resources were measured using the position generator (Lin, 2001; Van der Gaag, 2005). This instrument asks people about their network members' occupational positions and considers these positions as good indicators of the network resources. Position generators have already been used in health studies (Carpiano \& Hystad, 2011; Moore et al., 2009; Moore et al., 2011; Song, 2011; Song \& Lin, 2009). In this study, respondents were asked whether they know friends, relatives or acquaintances who have any of the jobs from a list of 11 occupations. All 11 occupations are salient in British society and range from factory worker to university/college lecturer (table 2).

In the literature, four approaches can be found to deal with the position generator answers (Verhaeghe, Van de Putte, \& Roose, 2013). We used all four approaches in this paper and compared their associations with self-rated health. The first approach is to calculate the volume of network resources 
by counting the number of different occupations accessed by respondents. This measure is related to the network size (Van der Gaag, 2005).

In the second approach, a component score of network resources is calculated, using the weighted sum of three indices: (1) volume of network resources, (2) highest occupational prestige score of the occupations accessed by respondents ('upper reachability'), and (3) range between the highest and lowest occupational prestige scores of the accessed occupations ('range'). ${ }^{3}$ This component score reflects the multidimensional nature of network resources. Following the British study of Li (2008), we used the Cambridge Social Interaction and Stratification Scale (Stewart et al., 1980) to assign occupational status scores to occupations. Status scores ranged from 4.14 (factory worker) to 84.75 (university/college lecturer). Weights for constructing the component score were derived from a principal components analysis ( .85 volume +.83 upper reachability +.93 range) .

In the third approach the average occupational status of network resources is calculated by dividing the sum of the status scores of accessed occupations by the total number of accessed occupations. This measure assesses the average quality of network resources. Respondents who did not know anyone involved in one of the 11 occupations, were assigned a zero-score.

In the fourth approach, accessed occupations are split up into different social classes in order to capture different types of resources. Only through this approach qualitative distinctions can be made between types of resources. We distinguished between three classes following the National Statistics Socio-economic Classification (Rose \& Pevalin, 2005). We calculated the number of accessed managerial and professional occupations in the position generator, the number of intermediate, lower supervisory or technical occupations, and the number of (semi-)routine occupations. This resulted in three interval class-based measures of network resources: salariat class resources (range: 0-4), intermediate class resources (0-3) and working class resources (0-4). 
We controlled for gender, age ${ }^{4}$, number of children in the household, and marital status. Moreover, we controlled for the highest educational attainment and social class position. Four educational categories were distinguished: 'higher education', 'higher middle education', 'lower middle education', and 'no qualification'. Following the National Statistics Socio-economic Classification, we distinguished between the salariat class (managerial and professional occupations), intermediate class (intermediate, lower supervisory and technical occupations, and small employers and own account workers), and working class (semi-)routine occupations, long-term unemployed, and people who have never worked).

Finally, we controlled for the sample wave and the length of residence in the area. ${ }^{5}$ The sample consists of two waves: '2006-2007' and '2007-2008'. Respondents were asked how long they have lived in their current area. The response categories were: ' $<12$ months', ' $\geq 12$ months, $<2$ years', ' $\geq 2$ years, $<3$ years', ' $\geq 3$ years, $<5$ years', ' $\geq 5$ years, $<10$ years', ' $\geq 10$ years, $<20$ years', and ' $\geq 20$ years'. We treated this variable as continuous for reasons of parsimony. ${ }^{6}$

\section{Neighbourhood deprivation}

Neighbourhoods were defined as the local super output areas (LSOAs) in England. The LSOAs were purposefully designed for research by the Office of National Statistics, using 2001 Census data (Martin, 2001). These geographical units have a minimum size of 1,000 residents and 400 households, and an average population of about 1,500 residents. There are in England 32,482 LSOAs. Our sample consists of 12,388 LSOAs. The neighbourhoods in our sample have, on average, 1.96 respondents. The number of respondents per neighbourhood ranges between 1 and $12 .^{7}$

The Office of the Deputy Prime Minister (2004) has compiled for each LSOA an aggregate Index of Multiple Deprivation. This index is based on the experienced levels of deprivation by residents in seven domains: income, employment, health, education, housing, crime, and living environment. We have linked the Index of Multiple Deprivation 2004 scores to the LSOAs in our sample. The use of 
these independent national data enhances accuracy, reduces measurement error, and alleviates concerns arising from the use of the same survey in calculating both individual and aggregate variables. This integral variable was especially preferred over aggregated variables, given the low average number of respondents per neighbourhood in our study.

\section{Analytic strategy}

Our data have a hierarchical structure: individuals (level 1) are nested within neighbourhoods (level 2). Because this violates the assumption of independence of observations (Hox, 2002), multilevel techniques were used with the Generalized Linear Latent and Mixed Models-command in Stata 10 (Rabe-Hesketh \& Skrondal, 2008). Linear multilevel regressions were performed for continuous dependent variables, whereas logistic multilevel regressions for binary variables, using Bernoulli response distribution and logit link. In logistic models, we calculated the intraclass correlation (ICC) by the formula: $\sigma^{2} /\left(\sigma^{2}+\pi^{2} / 3\right)$, where $\sigma^{2}$ is the neighbourhood variance. All models were estimated with maximum likelihood estimation using adaptive quadrature with 15 integration points. To make the intercept interpretable, we centred all continuous variables on their grand means.

To investigate whether and how different social capital elements are associated with self-rated health, we performed four logistic multilevel models with self-rated health as the outcome (Table 3). Each model contains the social capital elements trust, participation with friends, and participation with relatives, together with the individual control variables. The models differ in the specific network resource measures they contain (model 1: volume of network resources; model 2: component score of network resources; model 3: average occupational status of network resources; model 4: class-based measures of network resources). Due to multicollinearity, we could not model these four approaches together. The models are compared with each other using the log likelihoods. Only the approach that results in the best model fit will be used in the subsequent mediation analyses. We run each model with both unstandardized and standardized variables. Whereas the coefficients of unstandardized 
variables represent the correct estimates of the likelihood to report a good or very good health, the coefficients of standardized variables could be used to interpret the relative effect sizes.

Our investigation of the extent to which social capital mediates the relationship between neighbourhood deprivation and self-rated health consists of three steps. In step 1, we examine whether neighbourhood deprivation is related to social capital, after controlling for individual socio-economic and socio-demographic positions (Table 4). To establish a mediation effect, it is necessary for neighbourhood deprivation to be related to social capital. In step 2, we look at the associations between neighbourhood deprivation and social capital with self-rated health, using three logistic multilevel models (Table 5). In model 1, we examine the association between neighbourhood deprivation and self-rated health. In model 2, we add individual socio-economic and sociodemographic variables. In model 3, we add social capital. In this step, we use both unstandardized and standardized variables. Shrinkage of the effect of neighbourhood deprivation on self-rated health after taking social capital into account, would suggest that these variables are mediating the relationship between neighbourhood deprivation and self-rated health. In step 3, we formally test this mediation using product of coefficients tests for multilevel mediation models (see Supplementary Data Online) (Krull \& MacKinnon, 1999). We used first- and second order Taylor series expansions (Sobel and Aroian-tests) to provide estimates of the standard error of the mediated effect. ${ }^{8}$

\section{Results}

Table 1 reports the descriptive statistics for all variables. Due to missing data, 2,039 respondents were dropped from analyses, resulting in 23,327 respondents embedded in 11,875 neighbourhoods. Item non-response analyses showed that the excluded respondents were more likely to have a better selfrated health and to participate with friends. They were, however, less likely to participate with relatives and to have voluminous network resources (working class, intermediate class and to lesser extent salariat class network resources). 
Table 2 reports the occupational prestige scores, social class positions and distribution of the occupations in the position generator. Bivariate analyses showed that all social capital variables were positively associated with self-rated health and that neighbourhood deprivation was negatively associated with both self-rated health and social capital (see Supplementary Data Online).

\section{Individual social capital and self-rated health}

Table 3 shows that social capital matters for people's self-rated health, after controlling for individual background factors (Models 1-4). People who were trustful and who interacted frequently with friends and relatives had higher odds of good or very good health than their counterparts. The findings with respect to the network resources depended on the specific measures we looked at. Whereas the volume of network resources was not significantly related to self-rated health (Model 1), the component score of network resources (Model 2), the average occupational status of network resources (Model 3) and the class-based measures of network resources (Model 4) had significant associations. Likelihood ratio tests revealed that the fourth model was significantly better than the other three models, which indicated that the association between network resources and self-rated health was best captured with the class-based measures of network resources. Therefore, only these class-based measures were used in the subsequent mediation analyses.

Having more salariat class people than average in the individual's network increased the odds of good or very good health by 1.11 (Model 4). Although having more intermediate class people than average in the individual's network was positively correlated with self-rated health, this effect disappeared after controlling for the background variables. However, having more working class people than average in the individual's network decreased the odds of good or very good health $(\mathrm{OR}=0.90)$.

The relative effect sizes of social capital variables were compared by means of standardized odds ratios (Model 4, Table 3). The order of the effect sizes from large to small was participation with friends (St.OR=1.18), trust (St.OR=1.17), salariat class resources (St.OR=1.13), working class 
resources $(\mathrm{St} . \mathrm{OR}=0.89)$, participation with relatives $(\mathrm{St} . \mathrm{OR}=1.05)$, and intermediate class resources (St.OR=1.03; insignificant).

\section{Mediation analyses}

Table 4 shows that neighbourhood deprivation is strongly related to social capital. Residents of neighbourhoods which were more deprived than average, were less trustful $(\mathrm{OR}=0.98)$, participated less with friends $(\mathrm{OR}=0.99)$, participated less with relatives $(\mathrm{OR}=0.99)$, and had fewer salariat class people in their networks than average $(b=-0.007)$ and fewer people from the intermediate class $(b=-$ 0.004). However, inhabitants of neighbourhoods with higher levels of deprivation than the average, had more working class people in their networks than average $(b=0.001)$. The strong association between neighbourhood deprivation and social capital can especially be observed from the standardized coefficients (not shown, but available at Supplementary Data Online). Moreover, we found clear class and educational gradients in social capital.

The empty model of table 5 shows that English neighbourhoods differed significantly in their inhabitants' self-rated health. $5.11 \%$ of the variation in health could be attributed to the neighbourhood level. Model 1 shows that residents of neighbourhoods that were more deprived than the average were less likely to report good or very good health $(\mathrm{OR}=0.98)$. Moreover, after taking neighbourhood deprivation into account, the neighbourhood-level variance in self-rated health decreased from 0.177 (Model 0) to 0.086 (Model 1). Further analyses show that neighbourhood deprivation in the domains of income, education and health matter especially for self-rated health (see Supplementary Data Online).

Model 2 shows that the odds ratio of neighbourhood deprivation does not change much after taking individual background variables into account. The negative effect of neighbourhood deprivation on the likelihood to report good or very good health decreased with $6.8 \% \quad(=\ln (0.9827)$ $\ln (0.9839) / \ln (0.9827))$. It is noteworthy that the neighbourhood-level variance in self-rated health 
increased slightly from 0.086 (Model 1) to 0.092 (Model 2), after controlling for individual background variables.

The negative effect of neighbourhood deprivation on self-rated health further diminished after controlling for social capital, but remained significant (model 3). This suggests that the relationship between neighbourhood deprivation and self-rated health is partly mediated through social capital. However, the total mediation effect is rather small. The negative effect of neighbourhood deprivation on the likelihood to report good or very good health in model 3 decreased with $13.5 \%(=\ln (0.9839)$ $\ln (0.9860) / \ln (0.9839))$ in comparison with model 2. After controlling for social capital, the neighbourhood variance in self-rated health decreased again from 0.092 (Model 2) to 0.085 (Model 3).

Formal mediation tests reveal different mechanisms (see Supplementary Data Online). On one hand, residents of neighbourhoods that were more deprived than average were less trustful, participated less with friends and relatives, and had fewer salariat class people in their networks than average. These deficiencies in social capital result in poorer self-rated health. On the other hand, residents of neighbourhoods that were more deprived than average had more working class people in their networks than average, which resulted in poorer self-rated health too. Mediation test statistics showed that trust (Sobel test statistic $\mathrm{t}=-7.574)$ and participation with friends $(\mathrm{t}=-6.597)$ were most important in mediating the negative effect of neighbourhood deprivation, although salariat class resources $(t=-$ 4.733), working class resources $(\mathrm{t}=-2.571)$, and participation with relatives $(\mathrm{t}=-2.646)$ were important too. Having intermediate class people in the individual's network did not mediate the relationship between neighbourhood deprivation and self-rated health $(\mathrm{t}=-0.736)$.

\section{Discussion}

Individual social capital and self-rated health 
The first aim of this study was to examine the associations of individual social capital with self-rated health among the adult population of England. We found that generalized trust, participation with friends and relatives, and having salariat class people in the individual's network were associated with better self-rated health, after controlling for individual socio-demographic and socio-economic factors. Having trust and participating with friends were slightly stronger related with self-rated health than having network resources and participating with relatives. Although Moore (2011) has found similar findings in Montreal, this is the first study that establishes these associations among a large-scale national representative population. These results indicate that both the social cohesion-perspective (Fukuyama, 1995; Putnam, 2000) and network resource-perspective (Bourdieu, 1986; Lin, 2001; Portes, 1998) on social capital are important for explaining self-rated health and should be used in health research.

Our study further shows that the class-based measures of network resources are better at explaining self-rated health, than more commonly used measures (such as volume, component score and average occupational status of network resources). Moreover, the class-based measures reveal a social network gradient in health in addition to socio-economic gradients. After controlling for class and educational position, having more salariat class people in the individual's network than average is related to better self-rated health, whereas having more intermediate class people in the network is not related to selfrated health. In contrast, having more working class people in the individual's network is associated with poorer self-rated health. This social network gradient in health has been demonstrated before in Belgium (Verhaeghe et al., 2012) and suggests, in line with Portes (1998) and Moore (2009), that not all social capital is beneficial for health.

Both positive and negative associations between network resources and health could be explained by three types of mechanisms: neo-materialist mechanisms (Haines et al., 2011), socio-psychological mechanisms (Carpiano \& Hystad, 2011; Song, 2011), and health lifestyle mechanisms (Abel \& Frohlich 2012; Cockerham, 2005). Future research should explicitly test and compare these explanations. It is important to emphasize that for each explanation the negative health-consequences 
are not due to having socio-economically weak network members per se, but because of the socioeconomically weak resources of these network members.

\section{Neighbourhood deprivation and self-rated health}

The second aim of this study was to investigate the extent to which individual social capital mediates the relationship between neighbourhood deprivation and self-rated health. In line with other studies in England (Giordano et al., 2011; Lindström et al., 2004; Snelgrove et al., 2009), only a limited part $(5.11 \%)$ of the variation in self-rated health could be attributed to the neighbourhood level. This study shows, like many others (Diez Roux, 2001), that neighbourhood deprivation is negatively associated with individual self-rated health, after controlling for individual socio-economic and sociodemographic factors. In particular, deprivation in the domains of education, income and health seems to matter. Moreover, neighbourhood deprivation is responsible for almost half of the neighbourhood variance in self-rated health, even after controlling for individual background variables (the neighbourhood variance actually increases a bit after including these variables, which is not uncommon, see Lindström, 2004).

This negative relationship is partly mediated by trust and participation with friends, and to a lesser extent by salariat class and working class network resources. Although more research is needed, the lower levels of social capital in deprived areas could be explained by both neo-materialist (e.g. deprived areas offer less meeting opportunities to be socially involved) and psychosocial mechanisms (e.g. the stigmatised reputations of deprived areas and its people) (Cattell, 2001; Stephens, 2008).

However, this mediation effect is rather moderate, suggesting that other factors at the individual or neighbourhood level might be more important. In contrast, Haines (2011) found that the relationship between neighbourhood disadvantage and having depressive symptoms in a midsized southern city in the United States was largely mediated through network resources. There are several explanations for these divergent findings. Whereas our study used self-rated health as the outcome variable, Haines et 
al. (2011) used depressive symptoms. As Ziersch (2005) suggested, social ties might be especially important for mental health. Moreover, we used network members' class positions to assess network resources, whereas Haines (2011) used the average educational level of network members and the proportion that is employed and owns working cars. Furthermore, the variation in neighbourhood deprivation is reasonably higher in England than in a midsized southern city in the United States.

\section{Study limitations}

Firstly, because of the cross-sectional design we have to be cautious about the causality of the (mediating) associations. It could be argued, for example, that people with bad health participate less in social life, and have, therefore, less opportunities to meet people (from both the working and salariat class) and to acquire trust in others. Secondly, our study assessed socializing with friends and relatives and did not take participation in formal associations into account. Although some health studies also used social participation with friends and relatives to measure social capital in the social cohesion-tradition (Veenstra, 2000; Ziersch, 2005), measures of participation in formal organizations are more commonly used (Fujiwara \& Kawachi, 2008; Giordano et al., 2011; Snelgrove et al., 2009; Ziersch, 2005). Thirdly, the small scale of the LSOA-neighbourhoods is one of the study's strengths. The drawback is that the average number of respondents per neighbourhood was very small. Nevertheless, having many group level-units is more important in multilevel analyses than having many respondents per group level-unit (Hox, 2002) and supplementary analyses with neighbourhoods with five or more respondents resulted in similar conclusions.

\section{Policy implications}

Firstly, in line with previous English research (Cattell, 2001; Li et al., 2008), different social capital elements were shown to be affected by structurally anchored socio-economic life chances. Therefore, policy makers could encourage trust, social participation and network resources by tackling the root causes of socio-economic inequalities at the individual and neighbourhood level. Secondly, policy 
makers could support people who are disadvantaged in social capital with supplementary health assistance (e.g. through community workers). Finally, as argued by Abel and Frohlich (2012), policy makers could promote disadvantaged people to effectively invest their limited social capital in order to realize 'structurally transformative agency'. In the British context, this means that the government should replace budget cutting by investing in durable employment programmes, excellence in nonpublic schools, neighbourhood improvement, accessible health care systems and empowerment programmes. 


\section{References}

Abel, T., \& Frohlich, K.L. (2012). Capitals and capabilities: linking structure and agency to reduce health inequalities. Social Science \& Medicine, doi: 10.1016/j.socscimed.2011.10.028

Acock, A.C., \& Hurlbert, J.S. (1993). Social networks, marital status, and well-being. Social Networks, 15(3), 309-334.

Aneshensel, C.S., \& Sucoff, C.A. (1996). The neighbourhood context of adolescent mental health. Journal of Health and Social Behavior, 37(4), 293-310.

Aust, R.A., \& Vine, L. (2007). Taking Part: National Survey of Culture, Leisure and Sport. London: Department for Culture, Media and Sport.

Bourdieu, P. (1986.) Forms of capital. In J. Richardson (Ed), Handbook of theory and research for the sociology of education (pp. 241-258). New York: Greenwood.

Carpiano, R.M. (2006). Toward a neighborhood resource-based theory of social capital for health: Can Bourdieu and sociology help? Social Science \& Medicine, 62(1), 165-175.

Carpiano, R.M. (2007). Neighborhood social capital and adult health: an empirical test of a Bourdieubased model. Health \& Place, 13(3), 639-655.

Carpiano, R.M., \& Hystad, P.W. (2011). "Sense of community belonging" in health surveys: what social capital is it measuring. Health \& Place, 17(2), 606-617.

Cattell, V. (2001). Poor people, poor places, and poor health: the mediating role of social networks and social capital. Social Science \& Medicine, 52(10), 1501-1516. 
Cockerham, W.C. (2005). Health lifestyle theory and the convergence of agency and structure. Journal of Health and Social Behavior, 46(1), 51-67.

Diez-Roux, A.V. (2001). Investigating neighborhood and area effects on health. American Journal of Public Health, 91(11), 1783-1789.

Drukker, M., Kaplan, C., Feron, F., \& van Os, J. (2003). Children's health-related quality of life, neighbourhood socio-economic deprivation and social capital. A contextual analysis. Social Science \& Medicine, 57(5), 825-841.

Ferlander, S. (2007). The importance of different forms of social capital for health. Acta Sociologica 50(2), 115-128.

Fujiwara, T., \& Kawachi, I. (2008). A prospective study of individual-level social capital and major depression in the United States. Journal of Epidemiology and Community Health, 62, 627-633.

Fukuyama, F. (1995). Trust: the social virtues and the creation of prosperity. London: Hamish Hamilton.

Giordano, G.N., \& Lindström, M. (2010). The impact of changes in different aspects of social capital and material conditions on self-rated health over time: a longitudinal cohort study. Social Science \& Medicine, 70(5), 700-710.

Giordano, G.N., Ohlsson, H., \& Lindström, M. (2011). Social capital and health - Purely a question of context? Health \& Place, 17(4), 946-953. 
Haines, V.A., Beggs, J.J., \& Hurlbert, J.S. (2011). Neighborhood disadvantage, network social capital, and depressive symptoms. Journal of Health and Social Behavior, 52(1), 58-73.

Hox, J. (2002). Multilevel Analysis. Techniques and Applications. London: Lawrence Erlbaum.

Hyyppä, M.T., Mäki, J., Impivaara, O., \& Aromaa, A. (2007). Individual-level measures of social capital as predictors of all-cause and cardiovascular mortality. European Journal of Epidemiology, 22(9), 589-597.

Idler, E.L., \& Benyamini, Y. (1997). Self-rated health and mortality: a review of twenty-seven community studies. Journal of Health and Social Behavior, 38(1), 21-37.

Kawachi, I., \& Berkman, L.F. (2001). Social ties and mental health. Journal of Urban Health, 78(3), $458-467$.

Kawachi, I., Subramanian, S.V., \& Kim, D. (2008). Social capital and health. A decade of progress and beyond. In I. Kawachi, S.V. Subramanian, \& D. Kim (Eds.), Social Capital and Health (pp.1-26). New York: Springer.

Krull, J.L., \& MacKinnon, D.P. (1999). Multilevel mediation modelling in group-based intervention studies. Evaluation Review, 23(4), 418-444.

Li, Y., Savage, M., \&Warde, A. (2008). Social mobility and social capital in contemporary Britain. British Journal of Sociology, 59(3), 391-411.

Lin, N. (2001). Social capital: a theory of structure and action. London: Cambridge Press. 
Lindström, M., Moghaddassi, M., \& Merlo, J. (2004). Individual self-reported health, social participation and Neighbourhood. Preventive Medicine, 39(1), 135-141.

Martin, D. (2001). Geography for the 2001 Census in England and Wales. London: National Statistics.

McCulloch, A. (2003). An examination of social capital and social organisation in neighbourhoods in the British household panel study. Social Science \& Medicine, 56(7), 1425-1438.

Mohan, J., Twigg, L., Barnard, S., \& Jones, K. (2005). Social capital, geography and health: a smallarea analysis for England. Social Science \& Medicine, 60(6), 1267-1283.

Moore, S., Bockenholt, U., Daniel, M., Frohlich, K., Kestens, Y., \& Richard, L. (2011). Social capital and core network ties: a validation study of individual-level social capital measures and their association with extra- and intra-neighborhood ties, and self-rated health. Health \& Place, 17(2), 536544.

Moore, S., Daniel, M., Gauvin, L., \& Dubé, L. (2009). Not all social capital is good capital. Health \& Place, 15(4), 1071-1077.

Moore, S., Daniel, M., Paquet, C., Dubé, L., \& Gauvin, L. (2009). Association of individual network social capital with abdominal adiposity, overweight and obesity. Journal of Public Health, 31(1), 175183.

Nieminen, T., Martelin, T., Koskinen, S., Aro, H., Alanen, E., \& Hyyppä, M. (2010). Social capital as a determinant of self-rated health and psychological well-being. International Journal of Public Health, 55(6), 531-542. 
Office of the Deputy Prime Minister (2004). The English Indices of Deprivation 2004 (revised). London.

Pattyn, E., Van Praag, L., Verhaeghe, M., Levecque, K., \& Bracke, P. (2011). The association between residential area characteristics and mental health. Archives of Public Health, 69(3), doi:10.1186/07787367-69-3.

Poortinga, W. (2006). Social relations or social capital? Individual and community health effects of bonding social capital. Social Science \& Medicine, 63(1), 255-270.

Portes, A. (1998). Social capital: its origins and applications in modern sociology. Annual Review of Sociology, 24, 1-24.

Putnam, R.D. (2000). Bowling alone, the collapse and revival of civic America. New York: Simon \& Schuster.

Rabe-Hesketh, S., \& Skrondal, A. (2008). Multilevel and longitudinal modelling using Stata. Second edition. Texas: Stata.

Rose, D., \& Pevalin, D.J. (2005). The National Statistics Socio-economic Classification: origins, development and use. University of Essex: ISER.

Ross, C.E., \& Mirowsky, J. (2001). Neighborhood disadvantage, disorder, and health. Journal of Health and Social Behavior, 42(3), 258-276.

Simon, J.G., De Boer, J.B., Joung, I.M.A., Bosma, H., \& Mackenbach, J.P. (2005). How is your health in general? A qualitative study on self-assessed health. European Journal of Public Health, 15(2), 200-208. 
Smith, K., \& Christakis, N. (2008). Social networks and health. Annual Review of Sociology, 34, 405429.

Snelgrove, J.W., Pikhart, H., \& Stafford, M. (2009). A multilevel analysis of social capital and selfrated health: evidence from the British Household Panel Survey. Social Science \& Medicine, 68(11), 1993-2001.

Song, L. (2011). Social capital and psychological distress. Journal of Health and Social Behavior, 52(4), 478-492.

Song, L., \& Lin, N. (2009). Social capital and health inequality: evidence from Taiwan. Journal of Health and Social Behavior, 50(2), 149-163.

Stafford, M., De Silva, M., Stansfeld, S., \& Marmot, M. (2008). Neighbourhood social capital and common mental disorder: testing the link in a general population sample. Health \& Place, 14(3), 394405.

Stephens, C. (2008). Social capital in its place: using social theory to understand social capital and equalities in health. Social Science \& Medicine, 66(5), 1174-1184.

Stewart, A., Prandy, K., \& Blackburn, R. (1980). Social stratification and occupations. London: Macmillan.

Tampubolon, G., Subramanian, S.V., \& Kawachi, I. (2011). Neighbourhood social capital and individual self-rated health in Wales. Health Economics. DOI: 10.1002/hec.1808 
Tofighi, D. \& MacKinnon, D.P. (2011). RMediation: An R package for mediation analysis confidence intervals. Behavior Research Methods, 43(3), 692-700.

Van der Gaag, M.P.J. (2005). Measurement of individual social capital. Groningen.

Veenstra, G. (2000). Social capital, SES and health: an individual-level analysis. Social Science \& Medicine, 50(5), 619-629.

Verhaeghe, P.P., Pattyn, E., Bracke, P., Verhaeghe, M., \& Van de Putte, B. (2012). The association between network social capital and self-rated health: Pouring old wine in new bottles? Health \&Place, $18(2), 358-365$.

Verhaeghe, P.P., Van de Putte, B., \& Roose, H. (2013). Reliability of position generator measures across different occupational lists: a parallel-test experiment. Field Methods, 24(1), In press.

Webber, M.P., \& Huxley, P.J., (2007). Measuring access to social capital: the validity and reliability of the resource generator-UK and its association with common mental disorder. Social Science \& Medicine, 65(3), 481-492.

Weden, M.M., Carpiano, R.M., \& Robert, S.A. (2008). Subjective and objective neighborhood characteristics and adult health. Social Science \& Medicine, 66(6), 1256-1270.

Wilson, W.J. (1987). The truly disadvantaged: the inner city, the underclass, and public policy. Chicago: University Press.

Ziersch, A.M. (2005). Health implications of access to social capital: findings from an Australian study. Social Science \& Medicine, 61(10), 2119-2131. 
TABLE 1. Descriptive Statistics ${ }^{a}$

\begin{tabular}{|c|c|c|c|c|}
\hline & Percent & Mean & S.D. & Range \\
\hline \multicolumn{5}{|l|}{ Individual variables $(\mathrm{n}=\mathbf{2 3 , 3 2 7})$} \\
\hline \multicolumn{5}{|l|}{ Self-rated health } \\
\hline Very poor, poor or fair health $(0)$ & $30.0 \%$ & & & \\
\hline Good or very good health (1) & $70.0 \%$ & & & \\
\hline \multicolumn{5}{|l|}{ Trust } \\
\hline Distrust (0) & $57.5 \%$ & & & \\
\hline Trust (1) & $42.5 \%$ & & & \\
\hline \multicolumn{5}{|l|}{ Participation with friends } \\
\hline Less often than once a month $(0)$ & $10.4 \%$ & & & \\
\hline Once a month or more (1) & $89.6 \%$ & & & \\
\hline \multicolumn{5}{|l|}{ Participation with relatives } \\
\hline Never $(0)$ & $3.1 \%$ & & & \\
\hline Less often than once a month or more (1) & $96.9 \%$ & & & \\
\hline \multicolumn{5}{|l|}{ Social network resources } \\
\hline Volume & & 3.44 & 2.64 & $0 / 11$ \\
\hline Component score & & 0.00 & 1.00 & $-1.50 / 2$ \\
\hline Average occupational status & & 32.69 & 18.99 & $0 / 84.75$ \\
\hline Salariat class resources & & 1.11 & 1.20 & $0 / 4$ \\
\hline Intermediate class resources & & 1.12 & 0.99 & $0 / 3$ \\
\hline Working class resources & & 1.21 & 1.20 & $0 / 4$ \\
\hline \multicolumn{5}{|l|}{ Gender } \\
\hline Male (0) & $43.9 \%$ & & & \\
\hline Female (1) & $56.1 \%$ & & & \\
\hline Age & & 50.60 & 18.20 & $16 / 99$ \\
\hline Number of children & & 0.52 & 0.94 & $0 / 8$ \\
\hline \multicolumn{5}{|l|}{ Marital status } \\
\hline Single $(0)$ & $20.0 \%$ & & & \\
\hline Married or co-habiting (1) & $55.8 \%$ & & & \\
\hline Widowed, divorced or separated (2) & $24.2 \%$ & & & \\
\hline \multicolumn{5}{|l|}{ Highest educational attainment } \\
\hline No qualification $(0)$ & $27.8 \%$ & & & \\
\hline Lower middle education (1) & $23.4 \%$ & & & \\
\hline Higher middle education (2) & $26.8 \%$ & & & \\
\hline Higher education (3) & $22.0 \%$ & & & \\
\hline \multicolumn{5}{|l|}{ Social class position } \\
\hline Working class $(0)$ & $30.9 \%$ & & & \\
\hline Intermediate class (1) & $35.5 \%$ & & & \\
\hline Salariat class (2) & $33.6 \%$ & & & \\
\hline Length of residence in area & & 5.46 & 1.88 & $1 / 7$ \\
\hline \multicolumn{5}{|l|}{ Wave } \\
\hline Wave 2006-2007 (0) & $48.5 \%$ & & & \\
\hline Wave 2007-2008 (1) & $51.5 \%$ & & & \\
\hline \multicolumn{5}{|l|}{ Neighbourhood variable $(n=11,875)$} \\
\hline Index of multiple deprivations & & 22.62 & 16.18 & $0.72 / 85.59$ \\
\hline
\end{tabular}


TABLE 2. Position Generator Occupations

\begin{tabular}{lccc}
\hline Occupation & $\begin{array}{c}\text { Occupational } \\
\text { Status Score }\end{array}$ & $\begin{array}{c}\text { Social Class } \\
\text { Position }\end{array}$ & \% Known \\
\hline University/college lecturer & 84.75 & Salariat & 26.3 \\
Solicitor & 73.51 & Salariat & 30.3 \\
Bank or building society manager & 64.84 & Salariat & 17.8 \\
Company secretary & 47.22 & Salariat & 36.5 \\
Clerical officer in national or local government & 41.55 & Intermediate class & 25.1 \\
Nurse & 37.75 & Intermediate class & 47.2 \\
Electrician & 22.85 & Intermediate class & 39.8 \\
Sales or shop assistant & 30.89 & Working class & 43.8 \\
Postal worker & 17.85 & Working class & 23.0 \\
Bus or coach driver & 14.20 & Working class & 20.4 \\
Factory worker & 4.14 & Working class & 33.5 \\
\hline
\end{tabular}


TABLE 3. Multilevel Logistic Regression of Social Capital on the Odds of Good or Very Good Self-Rated Health $\left(\mathbf{n}_{\mathrm{i}}=\mathbf{2 3 , 3 2 7} \text { and } \mathbf{n}_{\mathrm{j}}=11,875\right)^{\mathrm{a}}$

\begin{tabular}{|c|c|c|c|c|c|c|c|c|c|}
\hline & \multirow{2}{*}{$\begin{array}{c}\text { Model 0 } \\
\text { OR }(95 \% \text { CI }) \\
\end{array}$} & \multicolumn{2}{|l|}{ Model 1} & \multicolumn{2}{|l|}{ Model 2} & \multicolumn{2}{|l|}{ Model 3} & \multicolumn{2}{|l|}{ Model 4} \\
\hline & & OR $(95 \% \mathrm{CI})$ & $\begin{array}{l}\text { St. } \\
\text { OR }\end{array}$ & OR $(95 \% \mathrm{CI})$ & $\begin{array}{l}\text { St. } \\
\text { OR }\end{array}$ & OR $(95 \% \mathrm{CI})$ & $\begin{array}{l}\text { St. } \\
\text { OR }\end{array}$ & OR $(95 \% \mathrm{CI})$ & $\begin{array}{l}\text { St. } \\
\text { OR }\end{array}$ \\
\hline Intercept & $2.41(2.34 / 2.50)^{* * *}$ & $0.36(0.29 / 0.45)^{* * *}$ & 1.75 & $0.38(0.30 / 0.47)^{* * *}$ & 1.76 & $0.40(0.32 / 0.50)^{* * *}$ & 1.75 & $0.41(0.33 / 0.51)^{* * *}$ & 1.70 \\
\hline \multicolumn{10}{|l|}{ Individual level } \\
\hline Age & & $0.98(0.97 / 0.98)^{* * *}$ & 0.98 & $0.98(0.97 / 0.98)^{* * *}$ & 0.98 & $0.97(0.97 / 0.98)^{* * *}$ & 0.97 & $0.97(0.97 / 0.98)^{* * *}$ & 0.97 \\
\hline Female & & $1.20(1.13 / 1.28)^{* * *}$ & 1.09 & $1.20(1.12 / 1.28)^{* * *}$ & 1.09 & $1.18(1.10 / 1.25)^{* * *}$ & 1.08 & $1.15(1.08 / 1.23)^{* * *}$ & 1.07 \\
\hline Number of children & & $1.03(0.99 / 1.07)$ & 1.03 & $1.03(0.99 / 1.07)$ & 1.03 & $1.028(0.99 / 1.07)$ & 1.03 & $1.02(0.98 / 1.07)$ & 1.02 \\
\hline Married or co-habiting & & $1.47(1.34 / 1.60)^{* * *}$ & 1.21 & $1.45(1.33 / 1.59)^{* * *}$ & 1.20 & $1.46(1.34 / 1.59)^{* * *}$ & 1.21 & $1.48(1.35 / 1.62)^{* * *}$ & 1.22 \\
\hline Widowed, divorced or separated & & $0.97(0.87 / 1.08)$ & 0.99 & $0.97(0.87 / 1.07)$ & 0.99 & $0.97(0.88 / 1.08)$ & 0.99 & $0.99(0.89 / 1.10)$ & 0.99 \\
\hline Lower middle education & & $1.44(1.32 / 1.57)^{* * *}$ & 1.17 & $1.42(1.30 / 1.55)^{* * *}$ & 1.16 & $1.40(1.29 / 1.53)^{* * *}$ & 1.16 & $1.41(1.29 / 1.54)^{* * *}$ & 1.16 \\
\hline Higher middle education & & $1.60(1.47 / 1.76)^{* * *}$ & 1.23 & $1.57(1.44 / 1.73)^{* * *}$ & 1.23 & $1.54(1.41 / 1.70)^{* * *}$ & 1.22 & $1.53(1.40 / 1.68)^{* * *}$ & 1.21 \\
\hline Higher education & & $2.04(1.82 / 2.28)^{* * *}$ & 1.34 & $1.99(1.78 / 2.23)^{* * *}$ & 1.33 & $1.91(1.70 / 2.14)^{* * *}$ & 1.30 & $1.82(1.62 / 2.05)^{* * *}$ & 1.28 \\
\hline Intermediate class & & $1.34(1.24 / 1.44)^{* * *}$ & 1.15 & $1.33(1.23 / 1.43)^{* * *}$ & 1.15 & $1.31(1.22 / 1.42)^{* * *}$ & 1.14 & $1.29(1.20 / 1.40)^{* * *}$ & 1.13 \\
\hline Salariat class & & $1.62(1.47 / 1.78)^{* * *}$ & 1.25 & $1.60(1.45 / 1.75)^{* * *}$ & 1.24 & $1.56(1.42 / 1.71)^{* * *}$ & 1.23 & $1.51(1.38 / 1.66)^{* * *}$ & 1.21 \\
\hline Length of residence in area & & $0.98(0.96 / 1.00)$ & 0.97 & $0.98(0.96 / 1.00)$ & 0.97 & $0.98(0.96 / 1.00)$ & 0.97 & $0.99(0.97 / 1.01)$ & 0.97 \\
\hline Wave $2007-2008$ & & $1.02(0.96 / 1.08)$ & 1.01 & $1.02(0.96 / 1.09)$ & 1.01 & $1.02(0.96 / 1.09)$ & 1.01 & $1.02(0.96 / 1.09)$ & 1.01 \\
\hline Trust & & $1.40(1.32 / 1.50)^{* * *}$ & 1.18 & $1.40(1.31 / 1.49)^{* * *}$ & 1.18 & $1.39(1.31 / 1.49)^{* * *}$ & 1.18 & $1.38(1.30 / 1.48)^{* * *}$ & 1.17 \\
\hline Participation with relatives & & $1.34(1.13 / 1.58)^{* * *}$ & 1.05 & $1.33(1.12 / 1.57)^{* * *}$ & 1.05 & $1.32(1.11 / 1.56)^{* * *}$ & 1.05 & $1.35(1.14 / 1.59)^{* * *}$ & 1.05 \\
\hline Participation with friends & & $1.74(1.58 / 1.92)^{* * *}$ & 1.18 & $1.72(1.57 / 1.89)^{* * *}$ & 1.18 & $1.72(1.56 / 1.89)^{* * *}$ & 1.18 & $1.73(1.57 / 1.90)^{* * *}$ & 1.18 \\
\hline Volume & & $1.00(0.99 / 1.02)$ & 1.01 & & & & & & \\
\hline Component score & & & & $1.05(1.02 / 1.09)^{* * *}$ & 1.05 & & & & \\
\hline Average status of resources & & & & & & $1.01(1.00 / 1.01)^{* * *}$ & 1.10 & & \\
\hline Salariat class resources & & & & & & & & $1.11(1.07 / 1.14)^{* * *}$ & 1.13 \\
\hline Intermediate class resources & & & & & & & & $1.03(0.99 / 1.07)$ & 1.03 \\
\hline Working class resources & & & & & & & & $0.90(0.88 / 0.93)^{* * *}$ & 0.89 \\
\hline Log Likelihood & -14231.24 & -12804.38 & & -12800.50 & & -12789.14 & & -12770.58 & \\
\hline Variance neighborhood level (se) & $0.177(0.041)^{* * *}$ & $0.131(0.044)^{* *}$ & & $0.129(0.044) * *$ & & $0.127(0.044)^{* *}$ & & $0.120(0.044)^{* *}$ & \\
\hline $\operatorname{ICC}(\%)$ & $5.11 \%$ & $3.84 \%$ & & $3.77 \%$ & & $3.72 \%$ & & $3.52 \%$ & \\
\hline
\end{tabular}

${ }^{*} \mathrm{p}<0.05 ; * * \mathrm{p}<0.01 ; * * * \mathrm{p}<0.001 ;{ }^{\mathrm{a}}$ OR: Odds Ratio; St.OR: Standardized Odds Ratio 
TABLE 4. Multilevel Regression of Neighbourhood Deprivation on Social Capital $\left(n_{i}=\mathbf{2 3 , 3 2 7}\right.$ and $\left.n_{j}=11,875\right)$

\begin{tabular}{|c|c|c|c|c|c|c|}
\hline & Trust $^{\mathrm{a}}$ & $\begin{array}{c}\text { Participation with } \\
\text { friends }^{\mathrm{a}}\end{array}$ & $\begin{array}{l}\text { Participation with } \\
\text { relatives }^{\mathbf{a}}\end{array}$ & $\begin{array}{c}\text { Salariat class } \\
\text { resources }^{\mathbf{b}}\end{array}$ & $\begin{array}{c}\text { Intermediate class } \\
\text { resources }^{\text {b }}\end{array}$ & $\begin{array}{c}\text { Working class } \\
\text { resources }^{\mathrm{b}}\end{array}$ \\
\hline & OR $(95 \% \mathrm{CI})$ & OR $(95 \% \mathrm{CI})$ & OR $(95 \% \mathrm{CI})$ & $\mathrm{b}(95 \% \mathrm{CI})$ & $\mathrm{b}(95 \% \mathrm{CI})$ & $\mathrm{b}(95 \% \mathrm{CI})$ \\
\hline Intercept & $0.72(0.63 / 0.83)^{* * *}$ & $7.48(6.10 / 9.18)^{* * *}$ & $6.76(4.94 / 9.24)^{* * *}$ & $-0.90(-0.97 /-0.84)^{* * *}$ & $-0.54(-0.59 /-0.48)^{* * *}$ & $0.16(0.09 / 0.23)^{* * *}$ \\
\hline \multicolumn{7}{|l|}{ Neighbourhood level } \\
\hline Index of multiple deprivations & $0.98(0.98 / 0.98)^{* * *}$ & $0.99(0.99 / 0.99)^{* * *}$ & $0.99(0.98 / 0.99)^{* * *}$ & $-0.01(-0.01 /-0.01)^{* * *}$ & $-0.00(-0.01 /-0.00)^{* * *}$ & $0.00(0.00 / 0.00) * * *$ \\
\hline \multicolumn{7}{|l|}{ Individual level } \\
\hline Age & $1.01(1.01 / 1.02)^{* * *}$ & $0.97(0.97 / 0.97)^{* * *}$ & $0.99(0.98 / 0.99)^{* * *}$ & $0.01(0.01 / 0.01)^{* * *}$ & $-0.00(-0.01 /-0.00)^{* * *}$ & $-0.02(-0.02 /-0.01)^{* * *}$ \\
\hline Female & $0.84(0.79 / 0.89)^{* * *}$ & $0.99(0.90 / 1.08)^{* * *}$ & $1.52(1.30 / 1.78)^{* * *}$ & $0.09(0.06 / 0.12)^{* * *}$ & $-0.01(-0.03 / 0.02)$ & $-0.27(-0.30 /-0.24) * * *$ \\
\hline Number of children & $1.03(0.99 / 1.06)$ & $0.93(0.88 / 0.98)$ & $1.02(0.92 / 1.12)$ & $0.01(-0.01 / 0.03)$ & $-0.02(-0.03 /-0.00)^{*}$ & $-0.03(-0.05 /-0.01)^{*}$ \\
\hline Married or co-habiting & $1.03(0.95 / 1.13)$ & $0.78(0.68 / 0.89)^{* * *}$ & $2.85(2.35 / 3.45)^{* * *}$ & $0.13(0.09 / 0.17)^{* * *}$ & $0.20(0.17 / 0.24)^{* * *}$ & $0.29(0.24 / 0.33)^{* * *}$ \\
\hline Widowed, divorced or separated & $0.93(0.84 / 1.03)$ & $1.15(0.99 / 1.35)$ & $2.21(1.75 / 2.78)^{* * *}$ & $0.01(-0.04 / 0.06)$ & $0.09(0.05 / 0.13)^{* * *}$ & $0.20(0.15 / 0.26)^{* * *}$ \\
\hline Lower middle education & $1.09(1.00 / 1.20)^{*}$ & $1.29(1.14 / 1.47)^{* * *}$ & $1.52(1.22 / 1.91)^{* * *}$ & $0.36(0.32 / 0.41)^{* * *}$ & $0.29(0.26 / 0.33)^{* * *}$ & $0.24(0.19 / 0.28)^{* * *}$ \\
\hline Higher middle education & $1.17(1.07 / 1.28)^{* * *}$ & $1.42(1.25 / 1.61)^{* * *}$ & $1.45(1.16 / 1.82)^{* * *}$ & $0.53(0.48 / 0.57)^{* * *}$ & $0.38(0.34 / 0.42)^{* * *}$ & $0.17(0.13 / 0.22)^{* * *}$ \\
\hline Higher education & $1.69(1.52 / 1.87)^{* * *}$ & $1.55(1.32 / 1.83)^{* *}$ & $1.44(1.10 / 1.88)^{* *}$ & $0.89(0.84 / 0.94)^{* * *}$ & $0.30(0.26 / 0.35)^{* * *}$ & $-0.15(-0.20 /-0.09)^{* * *}$ \\
\hline Intermediate class & $1.13(1.05 / 1.22)^{* * *}$ & $1.28(1.15 / 1.42)$ & $1.18(0.98 / 1.43)$ & $0.30(0.26 / 0.33)^{* * *}$ & $0.24(0.21 / 0.27)^{* * *}$ & $0.03(-0.00 / 0.07)$ \\
\hline Salariat class & $1.27(1.16 / 1.39)^{* * *}$ & $1.40(1.22 / 1.60)$ & $1.14(0.91 / 1.44)$ & $0.51(0.47 / 0.56)^{* * *}$ & $0.30(0.26 / 0.33)^{* * *}$ & $-0.07(-0.11 /-0.02) * * *$ \\
\hline Length of residence in area & $1.01(0.99 / 1.03)$ & $1.14(1.11 / 1.16)^{* * *}$ & $1.21(1.17 / 1.26)^{* * *}$ & $0.03(0.03 / 0.04)^{* * *}$ & $0.05(0.05 / 0.06)^{* * *}$ & $0.09(0.08 / 0.09)^{* * *}$ \\
\hline Wave $2007-2008$ & $0.87(0.81 / 0.92)^{* * *}$ & $1.01(0.93 / 1.10)$ & $0.90(0.77 / 1.04)$ & $-0.00(-0.03 / 0.03)$ & $0.01(-0.01 / 0.04)$ & $0.02(-0.01 / 0.05)$ \\
\hline \multicolumn{7}{|l|}{ Model $0^{c}$} \\
\hline Log Likelihood & -15780.61 & -7777.46 & -3237.06 & -37167.13 & -32825.56 & -37329.48 \\
\hline Variance neighborhood level (se) & $0.601(0.053)^{* * *}$ & $0.033(0.078)$ & $0.074(0.236)$ & $0.142(0.012)^{* * *}$ & $0.072(0.008)^{* * *}$ & $0.128(0.011)^{* * *}$ \\
\hline Intraclass correlation $(\%)$ & $15.45 \%$ & $0.99 \%$ & $2.19 \%$ & $9.93 \%$ & $7.39 \%$ & $8.82 \%$ \\
\hline \multicolumn{7}{|l|}{ Model 1 ${ }^{\text {d }}$} \\
\hline Log Likelihood & -15232.69 & -7380.43 & -3066.51 & -34963.64 & -31755.31 & -36396.16 \\
\hline Variance neighborhood level (se) & $0.424(0.048)^{* * *}$ & $0.000(0.000)$ & $0.000(0.000)$ & $0.048(0.009)^{* * *}$ & $0.044(0.007)^{* * *}$ & $0.097(0.010)^{* * *}$ \\
\hline $\operatorname{ICC}(\%)$ & $11.44 \%$ & $0.00 \%$ & $0.00 \%$ & $4.11 \%$ & $4.91 \%$ & $7.32 \%$ \\
\hline
\end{tabular}

${ }^{\mathrm{a}}$ Logistic Multilevel Regression Models; ${ }^{\mathrm{b}}$ Linear Multilevel Regression Models; ${ }^{\mathrm{c}}$ Empty model; ${ }^{\mathrm{d}}$ Model with Individual and Neighbourhood variables 
TABLE 5. Multilevel Logistic Regression of Neighbourhood Deprivation and Social Capital on the Odds of Good or Very Good Self-Rated Health $\left(n_{i}=23,327 \text { and } n_{j}=11,875\right)^{a}$

\begin{tabular}{|c|c|c|c|c|c|c|c|}
\hline & \multirow{2}{*}{$\begin{array}{c}\text { Model 0 } \\
\text { OR }(95 \% \text { CI })\end{array}$} & \multicolumn{2}{|l|}{ Model 1} & \multicolumn{2}{|l|}{ Model 2} & \multicolumn{2}{|l|}{ Model 3} \\
\hline & & OR $(95 \% \mathrm{CI})$ & St. OR & OR $(95 \% \mathrm{CI})$ & St. OR & $\mathrm{OR}(95 \% \mathrm{CI})$ & St. OR \\
\hline Intercept & $2.41(2.34 / 2.50)^{* * *}$ & $2.40(2.32 / 2.48)^{* * *}$ & 2.40 & $1.06(0.92 / 1.23)$ & 1.67 & $0.52(0.42 / 0.66)^{* * *}$ & 1.66 \\
\hline \multicolumn{8}{|l|}{ Neighbourhood level } \\
\hline Index of multiple deprivations & & $0.98(0.98 / 0.98)^{* * *}$ & 0.75 & $0.98(0.98 / 0.99)^{* * *}$ & 0.77 & $0.99(0.98 / 0.99)^{* * *}$ & 0.80 \\
\hline \multicolumn{8}{|l|}{ Individual level } \\
\hline Age & & & & $0.97(0.97 / 0.97)^{* * *}$ & 0.97 & $0.97(0.97 / 0.97)^{* * *}$ & 0.97 \\
\hline Female & & & & $1.16(1.09 / 1.24)^{* * *}$ & 1.08 & $1.13(1.06 / 1.21)^{* * *}$ & 1.06 \\
\hline Number of children & & & & $1.04(1.00 / 1.08)$ & 1.04 & $1.04(1.00 / 1.08)$ & 1.04 \\
\hline Married or co-habiting & & & & $1.36(1.24 / 1.48)^{* * *}$ & 1.16 & $1.37(1.26 / 1.50)^{* * *}$ & 1.17 \\
\hline Widowed, divorced or separated & & & & $0.96(0.87 / 1.07)$ & 0.99 & $0.96(0.87 / 1.07)$ & 0.98 \\
\hline Lower middle education & & & & $1.38(1.27 / 1.51)^{* * *}$ & 1.15 & $1.33(1.22 / 1.46)^{* * *}$ & 1.13 \\
\hline Higher middle education & & & & $1.52(1.39 / 1.66)^{* * *}$ & 1.21 & $1.43(1.30 / 1.56)^{* * *}$ & 1.17 \\
\hline Higher education & & & & $1.95(1.75 / 2.18)^{* * *}$ & 1.32 & $1.69(1.50 / 1.89)^{* * *}$ & 1.24 \\
\hline Intermediate class & & & & $1.28(1.18 / 1.37)^{* * *}$ & 1.12 & $1.22(1.13 / 1.32)^{* * *}$ & 1.10 \\
\hline Salariat class & & & & $1.52(1.38 / 1.67)^{* * *}$ & 1.21 & $1.40(1.27 / 1.54)^{* * *}$ & 1.17 \\
\hline Length of residence in area & & & & $0.99(0.97 / 1.01)$ & 0.99 & $0.99(0.97 / 1.01)$ & 0.98 \\
\hline Wave $2007-2008$ & & & & $1.02(0.96 / 1.08)$ & 1.01 & $1.03(0.97 / 1.10)$ & 1.02 \\
\hline Trust & & & & & & $1.32(1.24 / 1.41)^{* * *}$ & 1.15 \\
\hline Participation with relatives & & & & & & $1.30(1.10 / 1.54)^{* * *}$ & 1.05 \\
\hline Participation with friends & & & & & & $1.69(1.54 / 1.86)^{* * *}$ & 1.17 \\
\hline Salariat class resources & & & & & & $1.09(1.05 / 1.13)^{* * *}$ & 1.11 \\
\hline Intermediate class resources & & & & & & $1.02(0.98 / 1.06)$ & 1.02 \\
\hline Working class resources & & & & & & $0.92(0.89 / 0.95)^{* * *}$ & 0.90 \\
\hline Log Likelihood & -14231.24 & -14042.637 & & -12817.24 & & -12681.08 & \\
\hline Variance neighborhood level (se) & $0.177(0.041)^{* * *}$ & $0.086(0.037)^{*}$ & & $0.092(0.042)^{*}$ & & $0.085(0.042)^{*}$ & \\
\hline $\operatorname{ICC}(\%)$ & $5.11 \%$ & $2.57 \%$ & & $2.72 \%$ & & $2.51 \%$ & \\
\hline
\end{tabular}

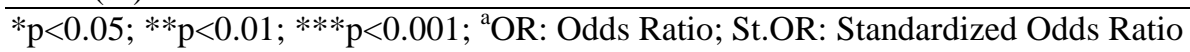




\footnotetext{
${ }^{1}$ Note that the results did not change substantially when we treated self-rated health as continuous (and using multilevel linear regression) or as ordinal (and using multilevel ordinal regression with five response categories).

${ }^{2}$ The cut-off point was clearly between 'less often than once a month' and 'once or twice a month' for participation with friends and between 'never' and 'less often than once a month' for participation with relatives (see Supplementary Data Online).
}

${ }^{3}$ These indices are strongly correlated (r: 0.827, 0.864 and 0.720$)$.

${ }^{4}$ The age range in the used sample is between 16 and 99. In supplementary analyses we confined the sample to respondents of 20 years or older. The results of these analyses were very similar to the results described in this paper (see Supplementary Data Online).

${ }^{5}$ As suggested by a reviewer, we additionally controlled for the type of area (urban versus rural area). Although there are small bivariate associations between this variable and self-rated health and social capital, this variable was insignificant in multivariate multilevel models (see Supplementary Data Online).

${ }^{6}$ In supplementary analyses we treated this variable as categorical (with the seven response categories). These analyses led to the same finding: length of residence in the area has no significant effect on health.

${ }^{7}$ In supplementary analyses we confined our sample to only neighbourhoods with five or more respondents. This restriction resulted in a sample of 3,108 respondents embedded in 538 neighbourhoods (see Supplementary Data Online). With this restricted sample, the associations of social participation with friends and relatives and having salariat class resources with self-rated health were less strong. Although the effect of neighbourhood deprivation on self-rated health was similar, there was not longer significant neighbourhood variance in health (probably due to the smaller number of neighbourhoods). Nevertheless, from these analyses we could draw similar conclusions regarding individual social capital as those presented in this paper.

${ }^{8}$ Because the confidence limits of the Sobel and Aroian-tests may be inaccurate, we additionally computed the confidence limits with the RMediation package of Tofighi and MacKinnon (2011). These analyses yielded the same results. 